\title{
DE LO POLÍTICO EN LA ACCIÓN: UN DIÁLOGO CON ESTHER FERRER
}

\author{
Diego Luna Delgado \\ Universidad de Sevilla. Doctor Internacional en Filosofía
}

\section{Resumen}

En este trabajo se plantean una serie de reflexiones sobre la actualidad del potencial político del arte suscitadas en una conversación mantenida con la artista Esther Ferrer. A partir de un uso de este material como fuente documental privilegiada, se propone un recorrido culturológico atendiendo a una comparativa entre, por un lado, algunas de las circunstancias y fenómenos que caracterizaron el contexto cultural franquista y, por otro, las nuevas formas de concebir el binomio arte-política y la lucha social en la actualidad.

\section{Palabras claves: FERRER, ESTHER; ARTE DE ACCIÓN; ARTIVISMO; ESTÉTICA; POLÍTICA}

\section{ABOUT POLITICS IN THE ACTION: A DIALOGUE WITH ESTHER FERRER}

Abstract

This paper presents a few reflections about the current importance of the art potential which were originated by a conversation with the artist Esther Ferrer. Using this material as a documental privileged source, a cultural analysis is proposed according to a comparative approach between, on the one hand, some circumstances and characteristics of francoist cultural context and, on the other hand, the new ways of thinking the art-politics binomial and the social struggle at present.

Keywords: ESTHER FERRER, PERFORMANCE ART, ARTIVISM, AESTHETICS, POLITICS

\section{AUSART}




\section{UN BREVE APUNTE INICIAL}

Si algo tuvieran en común las tesis y los debates generados en los últimos años acerca de la cultura, del, en, durante o bajo el franquismo, sería la apuesta, cada vez más compartida, por un modelo de estudio que permita establecer comparativas no jerárquicas entre lo oficial y lo marginal ${ }^{1}$. Esta visión horizontal de la que se parte como paradigma epistemológico en ningún caso implica ignorar las categorizaciones que el régimen imponía entre lo que podría ser, o no, incluido bajo la idea de "cultura". Más bien al contrario, lo que se proponen estos estudios transversales de los fenómenos culturales durante la dictadura es observar la interrelación que se estableció entre las expresiones institucionalizadas, permitidas y amparadas por el Estado, y aquellas otras subsumidas a un espacio de semi-clandestinidad y a una categoría siempre formulada en negativo: lo que no es cultura, lo que no es literatura, lo que noes arte, etc. Para este último caso en concreto, el de las manifestaciones artísticas, resulta especialmente necesario explorar los espacios de relación entre lo patrocinado y lo silenciado, de modo que podamos comenzar a descubrir dónde (cómo, por quién) se trazaban las fronteras entre el privilegio y el repudio institucional. Sin duda, un requisito esencial para poder llevar a buen término el propósito de analizar los espacios intersticiales de la cultura (o aunque solo sea, como en este caso, de las prácticas artísticas) es el estudio específico de los márgenes en los que crecieron las manifestaciones ajenas a los parámetros impuestos.

El interés que las prácticas experimentales han despertado en las últimas décadas debe ser leído ahora por los teóricos e historiadores del arte como la clara evidencia de la necesidad de reequilibrar sus objetos de estudio, de modo que las genealogías y los cánones sean revisados a la luz de los nuevos enfoques metodológicos. Por ello, podríamos acordar que el estudio de la cultura artística durante el franquismo ha necesitado proveerse a sí mismo de una agenda u hoja de ruta que marque las líneas fundamentales a desarrollar y que integre, entre sus objetivos, la comparación entre los territorios de la oficialidad y la marginalidad, así como la exploración de los espacios intersticiales que en su día produjo tal dicotomía. En este sentido, y dado que los estudios comparativos solo pueden construirse a partir de un conocimiento más o menos sólido de los elementos a cotejar, parece del todo evidente que la indagación sobre las zonas de exclusión institucional es primordial a la vez que urgente, ya que por todos es sabido que su otro extremo, el arte institucionalmente promovido, cuenta con una amplísima biografía que lo ha estudiado, reconocido y, en demasiadas ocasiones, legitimado acríticamente. ${ }^{2}$ 
El presente trabajo, elaborado a partir del testimonio recuperado de una figura artística hoy (tardíamente) reconocida y premiada por el Estado, pero en otro tiempo ignorada y hasta censurada por la dictadura, se inscribe en esta última línea de investigación. Más allá de un nuevo estudio sistemático de sus obras, empresa ya suficientemente cumplida ${ }^{3}$, creemos oportuno volcar una atención directa sobre las propias reflexiones de la artista para, a partir de ellas, construir vectores de análisis más amplios sobre las prácticas creativas periféricas de una dictadura que, en lo artístico, conocemos muy bien en sus expresiones permitidas, pero de la que aún desconocemos mucho sobre sus espacios y estrategias de oscurecimiento y exclusión artística.

\section{ARTE Y POLÍTICA DURANTE EL FRANQUISMO}

Por muchos y por variados motivos, el caso de la artista Esther Ferrer (San Sebastián, 1937) se presta como pocos al desarrollo de una nueva forma de concebir o construir nuestra memoria ${ }^{4}$. Testigo y partícipe de una época reconocidamente adversa a las libertades sociales, como fue la dictadura franquista, su figura, con el tiempo, ha llegado a simbolizar por sí misma el potencial político del gesto más allá de los marcos históricos y epistemológicos: la expresión tal cual que sabe ir del cuerpo a cualquier otra parte. El "arte de acción", de la que fuera pionera en España junto a Juan Hidalgo y Walter Marchetti ${ }^{5}$,constituye de hecho el último paso del proceso de desmaterialización de la obra de arte -usando el recurrente término que Lucy Lippard pusiera en circulación ([1973] 2004)-, en tanto que, al tratarse de una acción, esto es, un movimiento real con una determinada intención (incluso con una intención de no tener ninguna intención), existe la posibilidad de no precisar más que del propio cuerpo del artista, de su mera presencia. En Ferrer, Premio Nacional de Artes Plásticas (2008) y Premio Velázquez de Artes Plásticas (2014), el gesto es, sencillamente, como muestra su propia trayectoria, aquello que acaba -cuando no empieza- superando los opuestos: "Sabías que tenías que pagar un precio y todos estábamos dispuestos a pagarlo, por supuesto. Ni lo pensábamos, es que ni lo pensábamos". En un panorama artístico donde, como bien ha explicado Juan Albarrán $(2008,170)$, "se atesoraba una serie de valores universales que emanaban de una individualidad genial y que se condensaban en obras eminentemente realistas cuya promoción y difusión (léase instrumentalización) eran responsabilidad del Estado", las dificultades para las 
propuestas más arriesgadas no debieron ser pocas, si bien no obstante, como afirmaba la artista: "Estábamos muy contentos -yo por lo menos-de no existir para esta gente (...)".

Ya desde su juventud Ferrer supo perfectamente en qué debía centrar sus esfuerzos, cuáles eran las ideas que le eran convenientes retener y repensar y, sobre todo, por las que merecía la pena luchar: "Las ideas pasaban los Pirineos a pesar de todo, ¿eh? Y ya en aquella época yo había viajado. Y sobre todo nosotros vivíamos en el País Vasco y yo pasaba la frontera a comprar libros y a ver cine y a todo esto cuando me daba la gana". En este ir y venir surgía precisamente un tipo de clandestinidad impuesta de la que acabaría floreciendo, en muchas ocasiones, una suerte de complicidad social que elevaba aquel primer gesto nimio y fugaz, profundamente duchampiano y cageano, a la vez que zen en el caso de Ferrer, a una nueva categoría de acción: "Cuando tú hacías algo como lo que hacíamos nosotros, la gente decía: "Con esta estética... ¡Estos tampoco son franquistas! Esta no es la estética franquista del arte franquista, donc, son anti-franquistas como yo". Y en ese sentido se creaba una complicidad con el público que, aunque se riera de ti a muerte y te considerara loco, chalado y todo el resto, en alguna parte decían "estos también están de nuestro lado".

Vinculado a esta complicidad social encubierta, en los recuerdos de Esther Ferrer aparecía otro fenómeno no menos llamativo y, por supuesto, pasado generalmente por alto en los estudios sociológicos y antropológicos: la autosuficiencia vital a la que indirectamente impelía la dictadura. Un asunto que, lejos de resultar controvertido, adquiere todo su sentido, desde la perspectiva de la artista, en la medida en que funcionaba como doble acicate vital: por un lado, como desarrollo obligatorio de un valerse por sí mismo y, por otro, paralelo a este, como un afán por reinventarse continuamente ante las múltiples adversidades: "Sí, a mí me ayudó mucho esto del franquismo, por ejemplo, para vivir completamente al margen de todas las ayudas, las becas, etc. Yo nunca he pedido una beca a nadie, en mi vida. Si puedo hacer las cosas las hago y si no... Me las pago yo y si no me las pago... (...) Y es curioso tener que agradecer algo al franquismo, es que desde ahí nunca he tenido ganas de pedirle nada a nadie. Con Franco ni se te ocurría. Y yo he cogido esta dinámica de 'me lo hago yo, me lo pago yo' y tal". Dos factores que repercutirían a la larga en la configuración de una personalidad y unos planteamientos artísticos, como los de Ferrer y tantas otras figuras de la cultura española contemporánea, potencialmente autosuficientes. 
Se trataba en verdad de una actitud o sentimiento compartido por muchos frente a aquellos tres movimientos -autoritario, destructivo y conformista- en los que se basaba, según Erich Fromm, la "libertad negativa" ([1941] 2005). La inmanencia del gesto cotidiano suponía precisamente, frente a la naturaleza divina en la que se apoyaron ideológicamente los totalitarismos del siglo XX, esa libertad interior que escapaba a todo intento de coerción política y que, como ocurría en el caso de ZAJ, agrupación a partir de la que Ferrer entraría en el mundo de la acción y en la que desarrollaría gran parte de su carrera, servía como fundamento para establecer un espacio relacional alternativo en el que superar lo que Fromm ([1941] 2005, 45) identificaba como la "soledad moral". Ante la adversidad y la represión de una política fuertemente estetizada en torno a la figura de un caudillo-artista, la mejor manera de cultivar el compromiso social y la fortaleza interior era, a la inversa, mediante las posibilidades de una estética politizada (Alonso Paredes 2009) en la que, como Joseph Beuys defendía, todo el mundo podía ser un artista. Una vez asumidos los riesgos de intentar esquivar la censura desde la práctica artística, el propio vivir activamente, esto es, de una forma participativa, que propugnaban tanto ZAJ como su "pariente extranjero"Fluxus, acababa desbordando, de hecho, todos los límites simbólicos de lo que Rancière $(2009,24)$ denominase el "régimen estético de las artes".

Como explicaba Esther Ferrer, con el Mayo del 68 a las puertas, "todo el mundo se considera, la participación era obligatoria. Tú podías hacer lo que querías pero el otro podía decir 'oye, ¿qué estás haciendo? Esto es una mierda', quiero decirte, se contestaba todo: en las universidades a los profesores, en la calle a la policía. La contestación estaba allí, era fácil, entonces cuando hacías algo la gente se consideraba con el derecho a participar y sobre todo si se veían con algo que no entendían, eso era evidente". La propia corriente situacionista y su dérive, con Debord al frente, simbolizaban a la perfección el ánimo contestatario de una sociedad, o al menos de un importante sector de esta, que veía en el transitar y la ocupación de la calle el escenario idóneo para llevar a cabo su lucha. En realidad ya había sido el propio Artaud ([1938] 1978, 85), cuya concepción visceral del teatro constituye todo un claro precedente del arte de acción, quien apostó por una búsqueda de la verdad y de la vida liberada, no en el teatro, sino en la calle. Se trataba, en cualquiera de los casos, de una idea de apertura participativa que, empezada en fenómenos como ZAJ, aunque con evidentes matices respecto a su interpretación en el happening fluxusiano, culminaría en los noventa con las propuestas desarrolladas en la línea de lo que Nicolas Bourriaud (1998) denominase "estética relacional". Una nueva forma de entender la práctica artística que en muchos casos, sin 
embargo, empezaba a alejarse de la austeridad original de la acción y de su compromiso político.

\section{CONTEXTO Y FORMAS DE HACER HOY}

En una dictadura todo está claro: todo es político y, además, en una dirección o en otra. (...) En una dictadura tú sabes que no puedes colaborar con esto, o sea, punto y aparte. No puedes, pase lo que pase tú no.

La clara bipolaridad de aquel escenario descrito por Ferrer podía facilitar en gran manera la invención de modos de acción susceptibles de ser interpretados como la expresión de un posicionamiento vital o político (si es que no fuera lo mismo) discordante con el discurso oficial de la dictadura. En la actualidad, sin embargo, "no hay una dictadura, ahora todo es más confuso, más difícil de percibir, todo es recuperable a una velocidad vertiginosa". Nuestras sociedades "líquidas" - utilizando el célebre término de Zygmunt Bauman-, se basan, al contrario que la sociedad de masas, en una producción inmaterial, como es la de la información, y están interconectadas entre sí en una red global económica cuyos intereses transgreden frecuentemente los propios de los ciudadanos. Tras el triunfo del relato neoliberal argumentado por Fukuyama, la confluencia de múltiples intereses en un mismo espacio común, que es horizontal y que ya no es distinguible del resto -ya no es la antigua "esfera pública" del Estado moderno- complica al máximo las decisiones: "Tienes tantas razones para no hacer, para no aceptar, como para hacer, ¿comprendes?", decía Ferrer. La desorientación epistemológica lyotardiana, ha radicalizado sus consecuencias en una crisis que ha alcanzado no solo el ámbito económico, sino también el ético. Una situación que, en cualquiera de los casos, exige urgentemente, y en paralelo a una reflexión sobre la aparición de una nueva sensibilidad tecnológica, el replanteamiento de todos y cada uno de los canales de acción convencionales, así como la progresiva reinvención y perfección de espacios alternativos de construcción de la realidad social. Hablamos pues de un contexto cuya complejidad, más allá del "¿cómo hacer?" tan unido al mundo del arte, deviene para Esther Ferrer en una pregunta mucho más general y previa que no se presta a rodeos: “¿para qué sirve todo esto?”. 
En un mundo en el que, como apuntaba la artista, "ya solamente para vivir tienes que pagar" (haciendo alusión a gastos fijos como el de la Seguridad Social), la angustia y el miedo a perderlo todo, que, consciente o inconscientemente, fomentan los medios, es ciertamente lo único que nos detiene. Un problema estructural de sobras conocido cuya solución, pese a lo que a veces se intente simular, se encuentra prácticamente secuestrada por una versión radical de la ideología liberal que ve en la "alquimia de la estafa artística" -diría Rafael Argullol (2014)-, uno de sus mejores aliados. Se trata, como podemos deducir, de un auténtico magma de intereses ocultos en el que, peligrosamente, resulta harto complicado decantarse por lo que antaño fuera un sentido u otro de la política: los viejos fantasmas del fascismo y el comunismo están surgiendo de nuevo; por no hablar, como Esther Ferrer recordase, de los constantes ejemplos, denunciados casi a diario, de casos flagrantes de vejación, humillación, y, en los últimos tiempos, de corrupción política: "No hay límites, no hay ningún extremo, todo está permitido para el poder. Cada día un escándalo. Aquí hay dos o tres personajes que están condenados y se siguen presentando y siguen ganando, la gente les sigue votando. Pero bueno estos tíos... Los siguen votando y son los de Alí Babá y los cuarenta ladrones". De algún modo podríamos intuir que el hecho de que la gente pierda los estribos de sus propias vidas interesa, fundamentalmente, a las élites que la gobiernan; y "ya no es que sean las élites -decía Ferrer-, sino ¿en qué piensan las bases?". En una educación en la que el fomento del pensamiento crítico brilla por su ausencia, la "unidimensionalidad" marcusiana, contraatacada, eso sí, por algunos espacios de la resistencia cibernética, sigue estando a la orden del día.

Especialmente sensibilizada con las cuestiones de género, Ferrer ponía como ejemplo de educación maniquea los últimos debates suscitados en torno al matrimonio homosexual en Francia, así como con la intención de introducir en los libros escolares la idea de que el género es una construcción social: "Bueno, pues no sabéis las aberraciones que están diciendo, jahora hay quienes dicen que obligan a los niños a vestirse de niñas en la escuela!". El trasnochado sistema educativo actual, credencialista (Collins 1989), reproductor de lo mismo (Bourdieu \& Passeron 1996) y desinteresado en el desarrollo integral del individuo, continúa siendo, junto con los medios de comunicación, una de las herramientas predilectas de la llamada "pos-democracia" (Crouch 2004). Un régimen organizativo que hasta el momento ha sabido camuflar a la perfección una estructura piramidal cada vez más acusada por medio de toda una sofisticada labor de ingeniería social basada en la continua actualización de los mecanismos de ficcionalización, invisibilización, reversión y fagocitación. Todo un engranaje de producción de falsas apariencias que, igual que expli- 
case Bajtin ([1941] 2005) a propósito de Rabelais, encuentra en la dinámica de la cosmovisión carnavalesca, su propia esfera de libertad permitida. El grito de "Lo llaman democracia y no lo es" se escucha para, posteriormente, ser contestado con leyes como la Ley de Seguridad Ciudadana del Gobierno español.

La opacidad de la política-pop, la tergiversación y manipulación de los hechos a través de los medios o el desfase del sistema educativo y sus carencias para formar ciudadanos, son solo algunos de los síntomas que, de algún modo, nos obligan a seguir recurriendo a las mismas teorías críticas que en su día fueron formuladas sobre el trasfondo de los fascismos. El testimonio de Ferrer, como el de tantos otros ciudadanos, refleja una pregunta compartida por muchos: la de por qué nuestras democracias no parecen ser tales. Una cuestión que, definitivamente, parece estar relacionada con una estudiada labor de desinformación ante los ciudadanos, en base a la cual, paradójicamente, estos últimos emiten su voto cada cierto tiempo. La artista, en relación a estos temas de actualidad y a sus respectivas gestiones desde los organismos oficiales, demostraba enérgicamente su inquietud social, abierta y preocupada, que caracteriza su trabajo desde sus comienzos en el mundo de la acción a mediados de los años sesenta. Una inquietud compartida en realidad por muchos otros artistas que en aquellos momentos empezaron a concebir el arte como una herramienta crítica, en el sentido marcusiano, especialmente válida para la lucha social. Se trataba de la "sensibilidad de lo actual", como dijera José Luis Fernández de Castillejo $(1968,15)$, diplomático y poeta ZAJ, un modo de vivir que entendía el mundo como campo abierto de posibilidades y que, enfriando el suceso estético para evitar las "redundancias extremas", invitaba a la participación generalizada $(1968,23)$.

En este sentido, la dimensión experimental que rodeaba a las prácticas artísticas de aquellos momentos nos serviría como marco idóneo para trazar una comparativa entre los modos de hacer $-y$ sus intrínsecas implicaciones políticas- de entonces y de ahora. Una dimensión en la que, por lo general, debido entre otros motivos a una expansión radical de los límites creativos, la función del espectador comenzaba a cobrar una importancia inusitada: de algún modo se pretendía elevar la categoría de espectador del nivel participante al de auténtico creador. En el caso concreto del arte de acción, el componente participativo, recogido directamente del trasfondo cultural del momento, se establecía como requisito indispensable en una experiencia estética especialmente activa. Más allá del prototipo de público moderno que mediante su imaginación puede llegar a crear en su mente un sentido distinto al original de la obra, lo cierto es que la revolución de la experiencia estética de la segunda 
mitad del siglo XX -prefigurada, no obstante, por los dadaístas y su "antipúblico" (Fernández de Castillejo 1968, 51)- pasó por derrocar todo tipo de sintaxis lingüística: desarticulado el código, el espectador es uno más -junto al artista- inmiscuido en una vorágine de pensamiento puro. El "Silencio" de John Cage y, en general, sus ideas sobre la música como mera "organización de sonidos" que tanta influencia tendrían en artistas como Esther Ferrer (Cage [1961] 2005, 3), sintetizan a la perfección la idea de una "obra abierta" y "en movimiento", en los términos de Umberto Eco ([1962] 1984). Un tema, el de la recepción de la obra de arte por los espectadores, que, desde la perspectiva de Esther Ferrer, cobra siempre nuevos e inesperados significados: "El público, primeramente, era un público virgen. Ahora ya es un público leído $y$ escrito que sabe perfectamente lo que es la performance o cree saberlo. Eso lo primero, y lo segundo: completamente pasivo, que va a la performance como va al teatro. Y que se siente y juega el papel de espectador exactamente como estaba definido".

Según este diagnóstico, en los años sesenta, por una parte, era fundamentalmente la inexperiencia del público frente a aquellas nuevas formas de expresión, basadas en la idea de proceso, lo que de algún modo provocaba, sin que en muchas ocasiones se hiciera explícito, su introducción en la propia obra. Por otra parte, sin embargo, ocurre que en la actualidad ese mecanismo de choque ha quedado casi completamente invalidado; del porqué Ferrer estaba segura: "Por varias cosas, primeramente por la televisión. La televisión ha pasivizado muchísimo al espectador. Luego, porque la performance se teatraliza también mucho y al teatralizarse necesita al espectador que corresponde, ¿comprendes? O sea, pero si tú has de emplear luces, decorados, personajes, o sea, teatralizas el hecho performativo, no puedes permitirle al público participar en el momento en que tienes algo que proteger, ¿comprendes?". Dos factores, podríamos decir, uno externo - un contexto cultural espectacularizado donde la televisión sigue jugando un importante papel- y otro interno -particular de la propia evolución de la práctica artística en su fricción con otras esferas- que en último término determinan un giro negativo impropio del propósito original del arte de acción y de sus modos de hacer. En el caso de Ferrer, profundamente "minimalistas": "Por eso yo digo siempre que si me quitan el vaso pues ya encontraré otro. Pero si tengo un ordenador, luces, tal y cual, y tengo que poner alguien que me proteja todo ese material y, si no estoy presente, prepararlo, y luego ya...". Si hay algo que caracteriza el campo de la acción, como entre otros autores ha apuntado Gillo Dorfles (1979, 28-31), esa es la inversión dada entre la tradicional experiencia de la representación y lo que Fernández de Castillejo denominase la "actualidad indicativa" $(1968,13)$, esto es, la realidad que no ofrece posibilidad de duda. 
De algún modo, la excesiva sofisticación de lo que comenzó siendo tan solo un gesto cualquiera no hace, de hecho, sino desvelar el medio o canal en el que confluyen aquellos dos factores pasivizadores: la institución museística. Un ente público cuyo objetivo se basa en toda una contradicción: el deseo de rentabilizar económicamente unos productos culturales que son, por su especial naturaleza, identificaciones de la propia comunidad con la que se pretende hacer negocio. La institución, a partir de esta premisa, infiere en la desactivación de la acción por varios motivos; entre ellos, como señalaba Ferrer: "Te impone porque tiene un problema de seguridad, entre otras cosas, primeramente porque lo que quiere es que todo pase 'tá-tá-tá', como está escrito y como tiene que ser. Y luego porque si pasa algo le pueden hacer un proceso, porque ahora todo el mundo abre procesos a todo". En efecto, en el mismo momento en que la institución ha decidido interesarse por la performance, han aparecido una serie de condicionamientos inevitables que hacen que esta se teatralice y, por ende, que el público se comporte como tiene que comportarse: "Tienes que hacer dentro, en el marco que marca y condiciona. De la misma forma que se hace en formato televisión, las performances se hacen en formato institución".

\section{A MODO DE CONCLUSIÓN: LA ACTUALIDAD DEL ARTE CRÍTICO}

Yo lo único que pido a la gente con la que trabajo es que se dé cuenta de lo que está haciendo, que pueda conceptualizarlo: ¿por qué lo están haciendo?, ¿qué es lo que les interesa de la acción? Si les interesa o no les interesa. Si no les interesa que se dediquen a otra cosa, que no pasa nada. Y si les interesa que inventen la manera de hacerlo, que inventen la disciplina, que inventen la técnica $y$, sobre todo, que extraigan una idea de la cabeza porque sin ideas es muy difícil trabajar.

Las formas de hacer, muchas de ellas cada vez más constreñidas a un formato previo, encierran siempre, no obstante, cierta posibilidad de cambio. En un contexto social en que la desigualdad deviene alarmante, la búsqueda de alternativas se establece automáticamente como prioridad. Se trata, en el caso de la situación política actual, de una necesidad de cambio que, como intuye Esther Ferrer, no solo debe afectar a un giro en relación a los tradiciona- 
les posicionamientos ideológicos, sino, verdaderamente, a una reestructuración radical de los modos de hacer la política: "Si ya nadie cree en los políticos para qué les votamos. Tanto sigamos votando este sistema no cambia. Los políticos lo que quieren es que votes, aunque sea a la derecha, porque saben que mañana les tocará a ellos. Si no votas, saben que no les tocará". La idea de tránsito, de cambiar de un estado a otro, la impermanencia en el modo zen -toda una filosofía de vida- por la que Ferrer y tantos otros se sintieran atraídos en el contexto de la Contracultura, resurge y vuelve a reivindicarse, como tantas otras veces en la historia, frente a un sistema político caduco y hermético que parece beneficiar solo a unos pocos.

En la inevitabilidad del cambio observamos, en el caso concreto de Ferrer, el genuino pensamiento de una artista fiel a un principio impuro: ARTE = VIDA. Tanto un ámbito como otro permanecen intrínsecamente unidos, instalados ambos en una tensión definitivamente cambiante, "definitivamente inacabada" como el Grand Verre de Duchamp. Un estado de continua invención que llevó a Ferrer y a sus compañeros de ZAJ a inventarse a sí mismos, en un lugar como la España de Franco, partiendo prácticamente de la nada: "En el principio fue ZAJ", afirmó Hilario Álvarez (2007). Y es que, como pensaron Ferrer y tantos otros artistas en un contexto más amplio y más complejo, como fue el de la Guerra Fría, si el arte por sí mismo ya no servía para solucionar ni mejorar nada, ¿por qué seguir haciendo exclusivamente arte?: "No lo llamábamos arte pero tampoco lo excluíamos -decía Ferrer-. O sea, no hablábamos de arte, se hablaba del mundo de la acción, otros lo llamaban performance en los ochenta. Era el mundo de la acción. En un artículo se decía que nosotros hacíamos 'teatro musical', y se llamaba como fuera: hacías. Yo tampoco digo ahora que hago arte, no sé cómo decirte. Me preguntan ¿¿Tú eres artista? y digo sí, ¿qué vas a decir? Si no tienes que explicar durante tres horas lo que haces. Pues dices sí, pues artista, ¿por qué no? Más fácil, simple”.

Era en efecto el mundo de la acción, pero, en términos más generales, el mundo de lo que Rancière $(2011,59)$ reconociese como "arte crítico": aquel identificado con la "política del devenir-vida del arte", cuya naturaleza, capaz de soportar múltiples relaciones entre la estética y la política, viene dada por su propia autosupresión como realidad aparte. Un tipo de práctica que, en palabras del autor, "se propone hacer conscientes los mecanismos de dominación para transformar al espectador en actor consciente de la transformación del mundo" (ibíd.). Un objetivo, este último, que en el trabajo de Ferrer es llevado a cabo a partir, por un lado, de una reducción, casi absoluta a veces, de cualquier soporte material y, por otro, la conjunción de tres elementos funda- 
mentales: el espacio, el tiempo y la presencia. En ello se encontraría, desde el ámbito estético, el punto de inicio hacia lo que podríamos concebir como una urgente necesidad de volver a pensar el arte desde su propia heteronomía; no como realidad aparte -como así lo concibe la actividad cosificadora del mercado- sino, más bien, como potencial creativo dispuesto a subvertir las relaciones de poder de cualquier régimen de identificación sensible. Precisamente de la idea de cambio y de la relativización de las categorías estéticas y políticas surgirían, al fin, las que en el particular modo de hacer de Esther Ferrer podrían ser, desde nuestra perspectiva, algunas de las claves para proyectar el desarrollo de los nuevos modos de hacer hoy.

En primer lugar, la propia conciencia sobre la inevitabilidad del cambio: "No se puede parar el tiempo. O sea, hay que dejar que las cosas cambien, no se puede estar repitiendo lo mismo que se hacía. Es lo que le digo a los chicos en los seminarios. Si repiten lo que ya está hecho es puro teatro y, además, iqué aburrimiento! Entonces, la performance hay que dejarla evolucionar y si desaparece, pues fíjate, también desaparecieron los dinosaurios y no ha pasado nada, ¿eh?". Insertos en una situación crítica a todos los niveles, producida, entre otros motivos, por haber elegido prácticamente lo mismo durante décadas por temor a lo no experimentado, la oportunidad de cambiar el rumbo político se estima hoy como prioridad absoluta. Podríamos comprobar, en este sentido, que de algún modo el componente procesual de las prácticas artísticas experimentales de los años sesenta del siglo $\mathrm{XX}$, herederas del llamado arte conceptual y de toda una tradición vanguardista interesada en reivindicar la "idea" de la obra, comporta una importante enseñanza para afrontar, de un modo estético pero también político, la realidad social actual. Así lo vemos explícitamente en el fascinante Autorretrato en el tiempo de Ferrer y, en general, allí donde la propia capacidad inventiva del arte moderno y contemporáneo, dependiente de un desarrollo profundo de la intuición y la reflexión, constituya uno de los aspectos fundamentales para fluir con este cambio. El principio de "no-obstrucción" de Cage es, después de todo, una herencia palpable en esa peculiar "incredulidad plástica" -utilizando la expresión de David Pérez $(2008,177)$ - de los medios que Ferrer utiliza.

En segundo lugar, derivado del primer punto, el rechazo a la añoranza. La vitalidad de Esther Ferrer es solo comparable a su propio interés en investigar el presente, es decir, las circunstancias que rodean su vida y su trabajo artístico. Desde el punto de vista de las nuevas generaciones, es posible sentir cierta melancolía respecto a ese componente agitador tan visible en las prácticas desarrolladas durante los años sesenta y setenta. Sin embargo, como 
apuntaba lúcidamente la artista: "No puedes buscar la misma cosa hoy en día. La situación es otra. Y por supuesto el problema es que hoy en día hay mucha gente que hace cosas pero es muy difícil que tú los conozcas, ese es el problema. Porque en realidad no conocemos más que lo que pasa por la institución, lo que pasa por las galerías, pero hay gente que intenta hacer cosas y cosas diferentes incluso en España". Fuera de los canales convencionales sigue habiendo alternativas $\mathrm{y}$, precisamente por ello, el problema principal no es la ausencia de creatividad, sino más bien la dificultad para encontrar esos espacios intermedios en un complejo entramado de relaciones radicalmente nuevo: "El problema yo creo que es añorar esos años. Los años pasaron, por ejemplo, mucha gente, mi generación, decíamos es como lo que hacíamos, las cosas que hacíamos, la lucha tal y cual... Pero es que no se puede ser paseísta, hoy en día hay que vivir lo que hay que vivir hoy en día. No hay que añorar, eso fue, pero es que añorar significa añorar a Franco. En España, nuestro caso concreto, significa añorar a Franco, porras. Pues yo no tengo ganas de añorarlo, verdaderamente, no tengo ningunas ganas. Entonces hay que ir a hacer lo que tú crees que hoy en día tienes ganas de hacer, quieres hacer y en otra parte de tu cabeza, debes hacer".

En tercer y último lugar, el antidogmatismo. Un valor que ha ocupado un lugar especial en la filosofía de la artista desde el comienzo de su carrera y que paradójicamente, en nuestra cultura occidental, marcada por tantos siglos de cristianismo, resulta ser un valor que aún hoy es objeto de animadversión por gran parte de la sociedad. En el caso de Ferrer, supone además un asunto de especial relevancia por tratarse, verdaderamente, de la base sobre la que apoya toda su metodología de trabajo: "Es cuando la gente me dice 'iAh, tú estás en contra!', y digo 'Yo no estoy en contra de nada, la gente que haga lo que quiera'. O sea, que el que quiera hacer performance y llamarlo teatro, eso es subjetivo, allá él, que haga lo que quiera, yo no he nacido para ser una dogmática y decir 'iLa performance es esto!'”. Al contrario, su obra, desde el principio de su trayectoria, ha estado regida por un principio de desconstrución de la sintaxis convencional de las cosas, esto es, por el absurdo y, en general, por la ruptura de los moldes. Así lo comprobamos, por ejemplo, en la célebre pieza de la artista Íntimo y personal. Frente a los manuales: la práctica y la experiencia de uno mismo; y frente a los juicios de valor, volviendo a la herencia duchampiana: la indiferencia para superar los opuestos.

Estos tres principios, finalmente, constituyen en conjunto lo que podríamos entender como parte importante de los cimientos de una nueva forma de pensar y concebir, no solo las prácticas artísticas contemporáneas, sino, fluyendo 
con su propia indefinición expansiva, los modos de construir la realidad social, de plantear la lucha social y de ejercer la resistencia. Una última reflexión, a este respecto, nos ofrecería Esther Ferrer para concluir nuestra conversación. Sobre el concepto de "activismo" la artista partía de la aclaración de su diferencia en los contextos de las últimas décadas del franquismo y el actual: "En la actualidad hay un concepto de activismo evidente que pasa por el concepto de activismo político clásico, de lucha, no de partido pero que funciona con una disciplina casi de partido. En nuestro caso, como os he dicho antes, era el que tenías tú y eso se expresaba de una manera dentro del arte". He aquí el reconocimiento explícito del potencial político de muchas de las prácticas artísticas desarrolladas a partir de los años sesenta, no contrario, sino complementario a la forma tradicional de manifestarse: "Entonces yo ahora siempre digo que cuando tengo una idea válida y puedo hacer una obra para manifestarme contra algo, por algo que pasa, si tengo una buena idea, yo estoy encantada”. Como defendía Slavoj Žižek: "No actúes jSolo piensa!” (2012).

La creatividad de la acción, reivindicada por sociólogos como Hans Joas para los movimientos sociales ([1997] 2013), aparece en este punto como la única posibilidad de ofrecer una respuesta al agotamiento de las formas pasadas. Conforme al cambio y no a la nostalgia por los antiguos modos de hacer, Esther Ferrer tiene presente que, aunque cada cual deba emprender sus propias investigaciones sobre las circunstancias que le rodean, también los lazos sociales están resurgiendo hoy día, como así lo demuestran los numerosos movimientos sociales de los últimos años. Como sabemos, son muchos además los nuevos instrumentos de cooperación y solidaridad basados en las posibilidades que ofrecen las redes digitales: "Me parece maravillosa la manera en la que pueden poner en contacto a la gente y hacer que en media hora se organice una manifestación. En ese sentido es maravilloso y yo estoy absolutamente contra todo control que pueda haber sobre la red. Para lo bueno y para lo malo. Todas las cosas tienen su parte buena y su parte mala dependiendo de cómo las utilices, pero, o sea, es muy peligrosa la red para el poder(...). Pero incluso para el optimismo es importantísimo. Yo creo que todos estos sistemas utilizados inteligentemente son muy poderosos".

En los nuevos medios de comunicación podría estar el germen de lo que, en el pensamiento de Esther Ferrer y de un cada vez mayor número de personas, constituiría el cambio más revolucionario y a la vez más necesario para mejorar cualquier situación de injusticia, de crisis estructural y de precariedad en la dimensión social. Un cambio no de lo general a lo particular, sino a la inversa, desde el interior, del trabajo individual de reflexión hacia fuera, 
hacia un ámbito de cooperación y de reparto de lo sensible auténticamente democrático: "Entonces, quizás, yo pienso que el interés de estos movimientos es que sean apolíticos, esa sería la gran victoria. Pero eso es muy difícil. Un movimiento que sea apolítico sin líderes se apoya en un concepto de la responsabilidad individual enorme". Se trataría, pues, de llevar nuevas posibilidades a la práctica -parafraseando la acepción propuesta por Esther Ferrer para la definición de ZAJ-, siempre y cuando esta acción fuera precedida de un proceso de autocrítica.

\section{Referencias}

Albarrán Diego, Juan. 2008 "Del desarrollismo al entusiasmo: Notas sobre el arte español en tiempos de transición". Foro de Educación 10

Alonso Paredes, Diego. 2009 "De la estetización de la política a la política a la estética". Revista de Estudios Sociales 34

Álvarez Díaz, Hilario. 2007 "El arte de acción en España: Una visión panorámica”. Conferencia impartida en la Academia de Teatro de Helsinki. http://www.accionmad.org/archivo/textos/ texto18.pdf

Argullol Murgadas, Rafael. 2014 "La alquimia de la estafa artística”. El País, 25 dic. http://elpais. com/elpais/2014/12/17/opinion/1418825697_312987.html

Artaud, Antonin. (1938) 1978 El teatro y su doble. Traducción de Enrique Alonso y Francisco Abelenda Barcelona: Edhasa

Bajtin, Mijail Mijaïlovich. (1941) 2005. La cultura popular en la Edad Media y en el Renacimiento: El contexto de François Rabelais. Versión de Julio Forcat y César Conroy.Madrid: Alianza

Bourdieu, Pierre \& Jean-Claude Passeron. 1996. La reproducción. Elementos para una teoría del sistema de enseñanza. Texto revisado por J. Melendres y M. Subirats. México DF: Fontamara

Bourriaud, Nicolas. 1998. L'esthétique relationnelle. Dijon: Presses du Réel

Cage, John. (1961) 2005. Silencio: conferencias y escritos de John Cage. Silencio. Traducción, Pilar Pedraza; epílogo, Juan Hidalgo. Madrid: Árdora

Collins, Randall. 1989. La sociedad credencialista. Sociología histórica de la educación y la estratificación. Radución, Ricardo Lezcano. Madrid: Akal

Crouch, Colin. 2004. Posdemocracia. Traducción de Francisco Beltrán.Madrid: Taurus

Dorfles, Gillo. 1979. “Happening y Body art”. En Happening de happenings y todo es happening: Documentos y testimonios sobre el I Congreso Internacional de Happening organizado por el C.I.T. "Comarca del Vallés". Granollers: Joan Illa Morell

Eco, Umberto. (1962) 1984. Obra abierta. Traducción de Roser Berdagué. Barcelona: Planeta-De Agostini 
Fernández de Castillejo, José Luis. 1968.Actualidad y participación: Una filosofía contemporánea. Madrid: Tecnos

Fromm, Erich. (1941) 2005. El miedo a la libertad. Traducción, Gino Germani. Buenos Aires: Paidós

Joas, Hans. (1997) 2013. La creatividad de la acción. Traducción de Ignacio Sánchez de la Yncera con la colaboración de Pedro Cordero Quiñones. Madrid: Centro Investigaciones Sociológicas

Lippard, Lucy R. (1973) 2004.Seis años: La desmaterialización del objeto artístico de 1966 a 1972. Traducción, $M^{a}$ Luz Rodríguez Olivares. Madrid: Akal

Parcerisasi Colomer, Pilar. 2007 Conceptualismos poéticos, políticos, periféricos: En torno al arte conceptual en España, 1964-1980. Madrid: Akal

Pérez Rodrigo, David. 1992. "El margen inconcluso: Juan Hidalgo y la promiscuidad ZAJ". Tesis Universitat Politècnica de València.

Pérez Rodrigo, David. 2008. Sin marco: Arte y actitud en Juan Hidalgo, Isidoro Valcárcel Medina y Esther Ferrer. València: Univ. Politécnica de València

Rancière, Jacques. (2004) 2011. El malestar en la estética. Traducido por Miguel Ángel Petrecca, Lucla Vogelfang \& Marcelo G. Burello. Buenos Aires: Capital Intelectual

Rancière, Jacques. (2000) 2009. El reparto de lo sensible: Estética y política. Traducción de Cristóbal Durán... et al. Santiago de Chile: LOM

Žižek, Slavoj. 2012. "Don’t act, just think!" Entrevista para Big Think. Vídeo de Youtube, 6:34. www.youtube.com/watch?v=lgR6uaVqWsQ

\section{Notas}

${ }^{1}$ Cualquier referencia bibliográfica al respecto pecaría de un reduccionismo imperdonable. Aun así, nos arriesgamos a citar las siguientes obras: para el estudio de la cultura franquista véanse los apartados correspondientes de J.P. Fusi Un siglo de España: La cultura (Barcelona: Marcial Pons, 1999); para la resistencia franquista desde la intelectualidad E. Díaz Ética contra política: los intelectuales y el poder (Madrid: Centro de Estudios Constitucionales, 1990); y del mismo autor, Los viejos maestros: La reconstrucción de la razón (Madrid: Alianza, 1994); en esta misma línea es obligada la referencia a S. Mangini Rojos y rebeldes: La cultura de la disidencia durante el franquismo (Barcelona: Anthropos, 1987). Para el estudio de la cultura durante el franquismo, y más concretamente, de la pervivencia de la tradición intelectual de la República, véanse J. Gracia Estado y cultura: El despertar de una conciencia crítica bajo el franquismo, 1940-1962 (Barcelona: Anagrama, 2006), y La resistencia silenciosa: Fascismo y cultura en España (Barcelona: Anagrama, 2004). Desde un enfoque disciplinar, y en lo que respecta a la literatura, es ya clásico la obra de J.C. Mainer Falange y literatura (Barcelona: RBA, 2013), cuya visión se puede complementar con M. Carbajosa y P. Carbajosa La corte literaria de José Antonio: La primera generación cultural de la Falange (Barcelona: Crítica, 2003).En el caso de las artes plásticas son una clara referencia para el estudio de la relación entre arte y propaganda las investigaciones de M. Cabañas Brazo La política artística del Franquismo: El hito de la Bienal Hispanoamericana de arte (Madrid: CSIC, 1996), así como J.L. Marzo ¿Puedo hablarle con libertad, excelencia?: Arte y poder en España desde 1950 (Murcia: CENDEAC, 2010). 
2 Un hecho que, visto desde otra perspectiva, no hace sino demostrar el grado de incomodidad suscitado en su día por parte de determinadas prácticas artísticas frente al orden oficialista aún superada la dictadura franquista. Como muestra de ello bastaría recordar que algunos de los considerados grandes constructores de la Historia del Arte español más reciente optasen en sus obras «fundacionales» por pasar por alto el trabajo desempeñado por artistas como los del grupo ZAJ durante la segunda mitad del siglo XX, o que, en el mejor de los casos, redujeran su mención a una tímida nota a pie de página. Hablamos de autores y obras como: V. Bozal Historia del Arte en España (Madrid: Istmo, 1972); S. Marchán Fiz Del arte objetual al arte de concepto (Madrid: Alberto Corazón, 1974); T. Llorens \& V. Bozal España, Vanguardia artística y realidad social: 1936-1976 (Barcelona: Gustavo Gili, 1976); o F. Calvo Serralleret al. España, Medio siglo de arte de vanguardia, 1939-1985 (Fundación Santillana/Ministerio de Cultura, 1985)

${ }^{3}$ Para una visión completa de la obra artística de Esther Ferrer sería imprescindible la consulta de los siguientes catálogos: Esther Ferrer: de la acción al objeto y viceversa (San Sebastián: Diputación Foral de Guipúzcoa-Koldo Mitxelena Kulturunea, 1997) y (Sevilla: Centro Andaluz de Arte Contemporáneo, 1998); Esther Ferrer: España en la XLVII Bienal de Venecia (Madrid: Ministerio de Asuntos Exteriores, 1999); T. Johnson Esther Ferrer: Poema de los números primos, Obra geométrica; La ciudad, un espacio para recorrer (Madrid: Ministerio de Fomento, 2000); Esther Ferrer: Al ritmo de tiempo (Madrid: Instituto Cervantes; San Sebastián: Diputación Foral de Guipúzcoa, 2006); Esther Ferrer: Trans/ acciones (México DF: Museo Universitario de Arte Contemporáneo-MUAC: Pértiga, 2009); Esther Ferrer: En cuatro movimientos (Madrid: Sociedad Estatal de Acción Cultural; Vitoria-Gasteiz: Fundación Artium de Álava, 2011); E. Ferrer Maquetas y dibujos de instalaciones, 1960-2011 (Madrid: Exit, 2011); y Esther Ferrer (Musée d'Art Contemporain du Valde-Marne: Frac Bretagne, 2014). Existe además un gran número de artículos aparecidos en prensa y otros escritos por la propia Esther Ferrer en el periódico El País entre 1976 y 1995 (http://elpais.com/autor/esther_ferrer/a/). Por último, vale la pena citar también el programa Metrópolis de TVE-2 dedicado a la artista con motivo de la exposición celebrada en Artium en 2011 (http://www.rtve.es/television/20111110/esther-ferrer/474451.shtml).

${ }^{4}$ Todas las citas de este artículo han sido tomadas de una entrevista realizada a Esther Ferrer el día 7 de junio de 2014 en su estudio de París. Hemos de agradecer la abierta disposición brindada por la artista desde el primer momento, así como la mediación del profesor Juan Bosco Díaz-Urmeneta para acordar este encuentro.

${ }^{5} \mathrm{Si}$ bien ellos tres fueron quienes constituyeron la formación más estable de ZAJ, fueron en realidad muchos más los que llegaron a pasar (dejando siempre 'propina', recordando el célebre cartón de Marchetti) a su peculiar 'bar': Ramón Barce, José Luis Castillejo, Tomás Marco, los hermanos José y Manuel Cortés, Ricardo Ferralt, Luis Martínez, Alejandro Reino, Eugenio de Vicente, Ramiro Cortés, Javier Martínez Cuadrado, Luis Mataix, Josefa Codorniú, Terele Pávez, el grupo OH (Paco Martínez, Juan Bober y Federico Millares), o los artistas fluxus Wolf Vostell, Alison Knowles y Dick Higgins. Mención aparte merece el artista Nacho Criado, figura indiscutible del conceptualismo español, de quien llegó a afirmar Juan Hidalgo que "no siendo ZAJ, ha sido desde el 71 el gran amigo de ZAJ" (citado en Pérez Rodrigo 1992, 230). 